\title{
Fast Initial Response Control Charts For Accounting Activities
}

Timothy C. Krehbiel, Miami University, USA

Jan E. Eighme, Miami University, USA

Douglas Havelka, Miami University, USA

\begin{abstract}
Although Six Sigma was developed to improve processes in a manufacturing environment, its use has expanded to many other areas including accounting and finance. We propose that control charts, originally used as tools for monitoring short-run manufacturing processes, can be effectively used in the Control Stage of Six Sigma projects designed to improve accounting processes with sparse data. We describe four of these control charts: (1) pre-control charts; (2) Shewhart control charts with dramatically reduced average run lengths (ARLs); (3) Cumulative Sum (CUSUM) control charts with fast initial response (FIR) enhancements; and (4) Exponentially Weighted Moving Averages (EWMA) control charts with FIR enhancements. We provide examples of FIR enhancements to CUSUM and EWMA control charts that can result in quicker detection of small shifts in the mean of accounting data.
\end{abstract}

Keywords: Six Sigma; Accounting; Control Charts; Fast Initial Response

\section{INTRODUCTION}

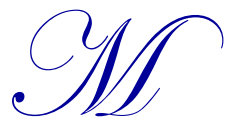

any companies are reaping the bottom-line benefits of Six Sigma. These benefits are the results of improvements to processes - both manufacturing and transactional. Six Sigma is a project-based process improvement initiative. One of the most predominate aspects of the Six Sigma methodology is the five-stage process improvement model: Define, Measure, Analyze, Improve, and Control (DMAIC). The DMAIC model has proven to be an effective method of data-driven decision making, leading to quality improvement and increased business performance. In the Define stage of the DMAIC model, a Six Sigma project team defines the problem and clarifies the scope of the project. In the Measure stage, the team collects data to analyze the problem and determine baseline performance. In the Analyze stage, the team determines the root cause(s) of the problem. In the Improve stage, the team designs and implements solutions to eliminate or minimize the root cause(s) of the problem. In the Control stage, the team uses on-going measurement and other tools to monitor the process and prevent the problem from occurring again.

Although Six Sigma was developed to improve processing in a manufacturing environment, its use has expanded to many other areas including accounting and finance. Brewer and Bagranoff (2004) report on the successful use of Six Sigma to eliminate inefficiencies in an accounts payable process. Brewer and Eighme (2005) and Krehbiel et al. (2009) report on the successful use of Six Sigma to improve the quarterly financial reporting process. Hostetler (2010) describes the results of a Six Sigma project designed to improve the income tax preparation processes in a CPA firm. Aghili (2009) discusses the use of Six Sigma projects to improve the efficiency of internal audits. Numerous Six Sigma applications concerning compliance with Section 404 of the Sarbanes-Oxley Act of 2002 have been reported (Stimson, 2004; Hofmann, 2005; Liebesman, 2005; LaComb \& Senturk, 2006; Senturk et al., 2006; Juras et al., 2007; Nanda, 2008; Ho \& Oddo, 2007). Many authors, including Neuschler-Fritsch \& Norris (2001), Friedman \& Gitlow (2002), and Rudisill \& Clary (2004, 2005) discuss accountants' roles and responsibilities in successful Six Sigma projects. Clearly not all accounting functions can reap improvements from Six Sigma. However, most functions are processes which produce output on a weekly, monthly, quarterly, or annual basis, and these processes are candidates for the use of statistical process control. 
The Control stage of the DMAIC model is critical for maintaining the improvements realized in the first four stages of a Six Sigma project. Some of the tools commonly used in the Control stage include documentation of standard operating procedures, balanced scorecards, and mistake proofing. Control charts are also a common tool in data-rich manufacturing Six Sigma projects. Walter A. Shewhart developed the control chart in the 1920s for use in determining whether assembly-line production processes were under statistical control. Thus, the technique takes advantage of, and requires the input of, large amounts of data collected frequently (e.g., hourly).

Because of the infrequency of data-collection points (e.g., weekly, monthly, or quarterly) in accounting processes, control charts can be difficult to implement to control these processes. Brewer \& Bagranoff (2004, page 71) argue that "While these less data-intensive processes can benefit from Six Sigma, control charts may not make sense in these situations." Therefore, control charts are not typically a tool used in the Control stage of Six Sigma accounting projects.

Advanced control charting methods have evolved, however, for situations that have less data and less frequent data-collection points. These tools are ideally suited for job-shop scenarios with small production runs and are often referred to as short-run manufacturing charts. Many business practitioners familiar with control charts are not familiar with these short-run control charting methods, and most business statistics textbooks ignore them altogether. Therefore, it is not surprising that these short-run methods are not part of the typical toolset for Six Sigma accounting projects.

\section{LITERATURE REVIEW}

Krehbiel et al. (2007) list five major areas where accounting processes lend themselves to control charts: financial reporting, internal auditing, external auditing, tax preparation, and business operations. Other discussions of the use of control charts in accounting are found in Reeve \& Philpot (1988), Roth (1990), Bruch (1994), Hutchins (2002), Long et al. (2002), Davies (2004), Stamitis (2003), Grabski (2004), and Marks \& Krehbiel (2009). Dull \& Tegarden (2004), Snee (2004) and Krehbiel et al. (2007) argue that use of control charts on accounting data will become more common.

Traditional Shewhart control charts typically consist of a center line that represents the mean $(\mu)$ of an in control process, an upper line that represents the upper control limit, and a lower line that represents the lower control limit. The limits are typically set at 3 sigma. That is, the upper limit is set at three standard deviations above the mean and the lower limit is set at three standard deviations below the mean. This chart is often referred to as a 3-sigma chart. Shewhart developed the control chart to be used to monitor assembly-line manufacturing processes in which frequent samples would be taken and a mean of the observations in the sample would be plotted on the control chart. In a 3-sigma control chart, $99.73 \%$ of observations plotted on the chart will fall within the control limits if the process is stable. If the plotted observations are randomly distributed about the center line within the limits, the variation is considered to be the result of random variation. However, if plotted observations are outside the limits or if they form a pattern (e.g., steadily increasing) within the limits, the control chart is considered to be signaling that the process may be unstable. Actions should be taken immediately to examine the process. 
Traditional Shewhart control charts were developed for monitoring assembly-line manufacturing processes with frequent data-collection points; therefore, it is difficult to implement them in situations where data collection is infrequent. As Table 1 indicates, there are more sophisticated tools than the traditional Shewhart control chart for monitoring such scenarios.

Table 1: Process Monitoring Tools for Sparse Data

\begin{tabular}{|l|c|}
\hline \multicolumn{1}{|c|}{ Technical Level } & Process Monitoring Tool \\
\hline \multirow{3}{*}{ Low } & Pre-Control Charts \\
\cline { 2 - 2 } & Shewhart Control Charts \\
\cline { 2 - 2 } & EWMA Control Charts \\
\cline { 2 - 2 } & CUSUM Control Charts \\
\hline \multirow{3}{*}{ High } & Modified Shewhart Control Charts \\
\cline { 2 - 2 } & EWMA Control Charts with Fast Initial Response Enhancement \\
\cline { 2 - 2 } & CUSUM Control Charts with Fast Initial Response Enhancement \\
\cline { 2 - 2 } & Combined EWMA and Shewhart Control Charts \\
\cline { 2 - 2 } & Combined CUSUM and Shewhart Control Charts \\
\hline
\end{tabular}

The simplest approach to monitoring is using pre-control charts. Pre-control charts are useful in start-up processes or processes with infrequent observations (Shainin \& Shainin, 1989; Logothetis, 1990; Mackertich, 2001; Krehbiel et al., 2007; Montgomery, 2009). Slightly more complicated are traditional Shewhart charts (e.g., X-bar \& $\mathrm{R}$, Individuals and Moving Range, $\mathrm{p}$, and c). Many Six Sigma training manuals identify Shewhart charts as part of a basic tool set. Discussions of this methodology can be found in these training manuals, as well as in textbooks concerning introductory business statistics, quality control, operations, and supply chain management. Several authors explore using Individuals charts and Moving Range charts with radically modified control limits to provide quicker detection of an unstable process (Rigdon et al., 1994; Amin \& Ethridge, 1998; Marks \& Krehbiel, 2009).

Cumulative Sum (CUSUM) control charts and Exponentially Weighted Moving Averages (EWMA) control charts are typically used to detect small shifts in the mean occurring over a relatively long period of time. However, both can be enhanced to provide a faster response to small shifts, and thus are applicable in some datasparse accounting scenarios. CUSUM control charts with a fast initial response (FIR) enhancement have been proven effective in short-run manufacturing environments (Lucas \& Crosier, 1982; Woodall \& Adams, 1993; Vardeman \& Jobe, 1999; Montgomery, 2009). Roughly equivalent to CUSUM control charts with an FIR enhancement are EWMA control charts with an FIR enhancement (Lucas \& Saccucci, 1990; Steiner, 1999; Rhoads et al., 1996; Montgomery, 2009). Although both FIR enhancements are well documented and implemented in manufacturing environments, there is currently little or no literature applying these methods to accounting/finance processes.

Albin et al. (1997) combine Individuals and EWMA control charts. Combined Individuals and CUSUM control charts are found in Lucas (1982). Setting up these combination charts to predetermined optimal settings is complicated. Furthermore, typical statistical software does not include such options, so customized programming is required for implementation. Moreover, reading and interpreting the charts is often confusing. Because of these limitations and complications, these combination charts are not illustrated in this paper.

\section{LOGIC OF SHORT-RUN MONITORING}

Farnum (1992) provides an overview of control charts for short-run manufacturing scenarios. When applying control charts to short-run manufacturing or to accounting processes, the infrequent data-collection points have serious implications on acceptable average run lengths (ARLs). Average run length is the average number of time periods a control chart goes without signaling an unstable condition. (For readers not familiar with control chart terminology, basic definitions and short discussions are provided in the Appendix.) A typical 3-sigma control chart will experience a false alarm indicating that a stable process is unstable (Type I error), on average, every 370 data-collection points. In other words, the All-OK ARL is approximately 370. So if data are collected hourly, as is often the case in a manufacturing setting, a false alarm will occur, on average, every 15.5 days. However, if a control chart is based on quarterly data, as is often the case in accounting processes, the same control chart will experience a false alarm every 92.5 years. Obviously, such huge protection from a false alarm is unwarranted. 
In general, decreasing the false alarm (Type I) error rate increases the probability of not detecting that a stable process has become unstable (Type II error), and vice versa. In other words, with a fixed sample size and data-collection frequency, increasing the All-OK ARL (a desirable result) also increases the probability of not detecting that a process has become unstable (an undesirable result), and decreasing the All-OK ARL (an undesirable result) increases the probability of detecting that a process has become unstable (a desirable result). We can easily reduce the All-OK ARL by placing control limits at some point less than 3-sigma. Specifically, if we move from a 3-sigma chart to a 2.3263-sigma chart, the All-OK ARL shrinks from 370 to 50 . Such a set-up is probably not a good idea for data collected hourly because a false alarm occurs approximately every four days. However, for quarterly data, a false alarm will only occur, on average, every 12.5 years. Therefore, if one can accept the higher false alarm rate (as is the case with data collected quarterly) one is rewarded with a control chart that is much more sensitive to change.

An important point to remember is that statistical methods are based on a set of assumptions. These assumptions are data driven, not functional driven. We must select the appropriate tool based on the type of data, not on a generalization based on the function from which the data are collected. It is not that control charts are not viable tools in accounting scenarios, it is that the type of control charts most business practitioners are familiar with are not viable for the type of data typically produced in the accounting function. Whereas the type of control charts used for data-rich manufacturing scenarios are not good candidates for the sparse data collected in many accounting processes, we must not jump to the conclusion that all control charts are not applicable.

The selection of the monitoring tool should be based on the properties of the data and the process, not the context of the setting. Koons \& Luner (1991) state that "Focusing on the process, not the product, is the key to implementing statistical process control in low-volume manufacturing environments." Hahn et al. (2000, page 324) note that "Effective MBBs [Master Black Belts] have become aware of the need of fitting the tools to the needs of their specific audience. Thus, in training and in qualifying BB [Six Sigma Black Belt] and GB [Six Sigma Green Belt] projects for certification they have learned not to insist dogmatically on the use of a specific tool, but to use or adapt the available tools to best meet the problem at hand." They go on to explain that beyond the basic statistical and Six Sigma toolset, that "...other powerful tools have proven their worth and warrant increased emphasis in future training. These will become increasingly more important as we move beyond the simplest situations (picking the proverbial "low-lying fruit") to more complex ones." The complex situation of concern in this paper is accountancy processes with sparse data.

\section{TOOLS FOR SHORT-RUN MONITORING}

\section{Pre-Control Charts}

Pre-control charts represent a non-statistical process-monitoring technique. Using judgment rather than rigorous statistical calculations, a Six Sigma team sets specification limits. Individual measurements are taken and then compared to these limits. A measurement that falls outside of the limits indicates the process is not meeting specifications and may be "out of control." Bhote (1991) describes the mechanics of pre-control using four easy rules:

1. Establish red, yellow, and green zones to evaluate whether a sample data point is within the defined specification limits (green is okay, yellow is caution, and red is trouble).

2. Sample the current process to determine whether it is currently in control.

3. Continue sampling periodically to monitor and evaluate the process.

4. For the periodic sampling in rule 3, determine how frequently it should be done.

Krehbiel et al. (2007) provide an accounting example of using pre-control charts to monitor whether variances between budgeted and actual manufacturing costs and budgeted and actual operating expenses indicate that the budgeting process is out of control. 


\section{Traditional Shewhart Control Charts with Shortened ARLs}

Shewhart developed the control chart to be used to monitor assembly-line manufacturing processes in which frequent samples would be taken and a mean of the observations in the sample would be plotted on the control chart. In processes where it is impossible or undesirable to take samples, such as small production runs, Individuals and Moving Range control charts are typically used to monitor the processes. These charts can also be used to control accounting processes that have infrequent data-collection points. Individuals charts plot individual measurements, and Moving Range charts plot the absolute difference between the current measurement and the previous measurement. An Individuals chart and a Moving Range chart may be presented in combination.

Statisticians have examined whether an Individuals chart alone or a combination of an Individuals chart and a Moving Range chart is best for detecting an unstable process. Most studies have concluded that the Individuals chart alone is sufficient (Nelson, 1982, 1990; Roes et al., 1993; Rigdon et al., 1994; Trip \& Wieringa, 2006; Marks \& Krehbiel, 2009). Adding a Moving Range chart decreases the sensitivity to detecting changes in the mean, and only slightly increases the sensitivity to detecting changes in variability. Therefore, they conclude that there is little value from using a Moving Range chart. They also conclude that the All-OK ARL (number of data points before a Type I error occurs) should be much shorter in situations where data are infrequently collected than in situations with frequently collected data. These findings indicate that an Individuals chart with a much shorter ALL-OK ARL than that used in manufacturing situations is suited for detecting an unstable process in an accounting scenario.

Marks and Krehbiel (2009) provide an accounting example of using an Individuals chart and a Moving Range chart with shortened ARLs to analyze weekly financial sales data to detect whether a sales process is unstable.

\section{CUSUM Control Charts with FIR Enhancement}

Cumulative Sum (CUSUM) control charts are more effective than Shewhart control charts when it is desired to detect small shifts in the mean. Small is roughly defined as two standard deviations or less. Moreover, a fast initial response (FIR) enhancement brings even quicker detection of small shifts. CUSUM control charts can be two-sided (designed to detect either an increase or a decrease in the mean) or one-sided (designed to detect a change in a pre-specified direction). For ease of presentation, we discuss only the upper one-sided case here.

We start with a sequence of values: $\mathrm{Q}_{1}, \mathrm{Q}_{2}, \mathrm{Q}_{3}, \ldots$, with mean and standard deviation $\mu$ and $\sigma$, respectively. The upper CUSUM statistic is then defined as:

$\mathrm{U}_{\mathrm{i}}=\max \left[0,\left(\mathrm{Q}_{\mathrm{i}}-\mathrm{k}_{1}\right)+\mathrm{U}_{\mathrm{i}-1},\right], \mathrm{i}=1,2,3, \ldots$

The $U_{i}$ are plotted and the process is deemed unstable if $U_{i}>$ the upper control limit (h). Values of $k_{1}$ and $h$ can be optimally selected to control false alarm rates and to give the quickest possible detection of a specified shift in the mean. In a typical CUSUM scheme:

$\mathrm{k}_{1}=\mu+\Delta / 2$

where $\Delta$ is the shift in $\mu$ one wishes to detect. Using the FIR enhancement, $U_{0}=h / 2$, i.e., the plotting of the CUSUM statistics start with a $50 \%$ headstart toward the upper control limit $\mathrm{h}$. Once the values of $\mu$ and $\Delta$ are determined, we can calculate $\mathrm{k}_{1}$ and select optimal values of $\mathrm{h}$ from Table 4.10 of Vardeman and Jobe (1999, page 155). The resulting CUSUM control chart will be much quicker to detect small shifts in the mean.

\section{Example of CUSUM Chart with Fast Initial Response}

A Six Sigma project designed to reduce the mean and variation in utility expenses was nearing completion. Improvements resulted in monthly expenses stabilizing with a mean of $\$ 35,000$ and a standard deviation of $\$ 2,000$. To ensure that these expenses do not increase, measures were set in place to help control the upstream variables causing high utility costs. In addition, the actual monthly utility expense is to be monitored. In order to have quick 
notification when changes have occurred, a one-sided CUSUM control chart with a FIR enhancement was constructed. The control scheme was designed to have an All-OK ARL of 50, i.e., a false alarm once every 50 months, and as quick as possible detection of increases as small as one standard deviation. Specifically, the optimally designed chart has an ARL of approximately 2 when the mean increases by one standard deviation. Note that a traditional 3-sigma Shewhart chart would be ineffective. That chart would have false alarms once every 370 months, on average, and take 43.86 months, on average, to detect a mean change to $\$ 37,000$. Also note that if a 2.33 -sigma Shewhart chart was used, the false alarm rate is 50 , and the detection of a one standard deviation change takes an average of 10.89 months.

Using the procedure outlined above, we have: $\mu=35,000, \sigma=2,000, \Delta=2,000, \mathrm{k}_{1}=36,000$, and $\mathrm{h}=4640$. Thus the process is said to be unstable if $U_{i}>4640$, where

$\mathrm{U}_{\mathrm{i}}=\max \left[0,\left(\mathrm{Q}_{\mathrm{i}}-36,000\right)+\mathrm{U}_{\mathrm{i}-1},\right], \mathrm{i}=1,2,3, \ldots$

and $\mathrm{U}_{0}=\mathrm{h} / 2=2320$.

Suppose that in the first month, utility expenses are $\$ 37,500$. We have $Q_{1}=37,500$ and

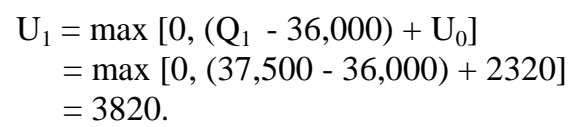

Thus, the process is deemed to be stable.

In the second month, utility expenses are $\$ 36,900$. We have $\mathrm{Q}_{2}=36,900$ and

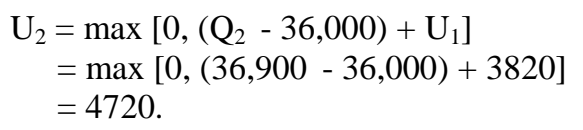

Because $U_{2}=4720>h=4640$, the chart signals an unstable condition and the process is deemed unstable. The CUSUM control chart has quickly identified an increase in the mean monthly utility expense. Management now has objective evidence that the improved conditions following the Improve Stage of the Six Sigma project no longer exist. Note that the change would not have been detected in either a 3-sigma Shewhart chart (upper control limit of 41,000) or a 2.33-sigma Shewhart chart (upper control limit of 39,660).

\section{EWMA Control Charts with FIR Enhancement}

The Exponentially Weighted Moving Averages (EWMA) control chart was developed in the late 1950s. The FIR enhancement was introduced thirty years later (Lucas \& Saccucci, 1990). As is the case with CUSUM control charts, EWMA control charts are more effective than Shewhart control charts when it is desired to detect small shifts in the mean. A FIR enhancement brings even quicker detection of small shifts, thus making it applicable to accounting processes with sparse data. The EWMA with FIR enhancement uses a headstart and can be two-sided (designed to detect either an increase or a decrease in the mean) or one-sided (designed to detect a change in a pre-specified direction). Only the upper one-sided case is presented here.

We start with a sequence of values: $\mathrm{Q}_{1}, \mathrm{Q}_{2}, \mathrm{Q}_{3}, \ldots$, with mean and standard deviation $\mu$ and $\sigma$, respectively. A smoothing constant, $\alpha$, is then used to smooth the series, where $0 \leq \alpha \leq 1$. The smaller the value of $\alpha$, the smoother the series becomes. The smoothed statistic is then defined as

$\mathrm{U}_{\mathrm{i}}=\alpha \mathrm{Q}_{\mathrm{i}}+(1-\alpha) \mathrm{U}_{\mathrm{i}-1}, \mathrm{i}=1,2,3, \ldots$

A typical EWMA chart plots $\mathrm{U}_{0}=\mu$, and control limits

$(\mathrm{LCL}, \mathrm{UCL})=\mu \pm 3 \sigma\left((\alpha /(1-\alpha))\left(1-(1-\alpha)^{2 \mathrm{i}}\right)\right)^{0.5}$. 
After a few observations, these control limits approach their asymptotic limits of

$(\mathrm{LCL}, \mathrm{UCL})=\mu \pm 3 \sigma(\alpha /(1-\alpha))^{0.5}$.

The FIR enhancement of a $50 \%$ headstart sets the initial smoothed statistic to a value half way between $\mu$ and a control limit.

Example of EWMA Chart with Fast Initial Response

Weekly sales (in thousands of dollars) have a mean of 25 and a standard deviation of 2. A smoothing constant $(\alpha)$ of 0.2 is utilized in the EWMA chart. Thus the asymptotic control limits are

$$
\begin{aligned}
(\mathrm{LCL}, \mathrm{UCL}) & =\mu \pm 3 \sigma(\alpha /(1-\alpha))^{0.5} \\
& =25 \pm 3(2)(0.2 / 0.8)^{0.5} \\
& =25 \pm 3 \\
& =22 \text { and } 28 .
\end{aligned}
$$

A 50\% headstart is used on the high side. Thus the initial plotted observation is $\mathrm{U}_{1}=26.5$, half-way between 25 and 28. Observations two through four are 27, 28, and 33. The smoothed statistic in observations two through four are:

$\mathrm{U}_{2}=(0.2)(27)+(0.8)(26.5)=26.6$

$\mathrm{U}_{3}=(0.2)(28)+(0.8)(26.6)=26.88$

$\mathrm{U}_{4}=(0.2)(33)+(0.8)(26.88)=28.104$.

The $\mathrm{U}_{4}$ statistic indicates an out-of-control signal at observation four. Without the FIR, the control chart would still indicate a stable process.

\section{SUMMARY AND CONCLUSION}

The Six Sigma process-improvement methodology has expanded from data-rich manufacturing settings to settings with infrequent data-collection points. Traditional Shewhart control charts are typically used to monitor processes in the Control stage of Six Sigma projects in manufacturing settings. This traditional chart is not appropriate for projects measuring accounting data that are collected infrequently. In this manuscript, we have proposed the use of several control charting techniques for these settings. We believe that all of these techniques should improve the quality and understanding of infrequent data-collection processes and prove valuable for organizations struggling to control and reduce the costs associated with them. Further research could be performed to test in what specific activities these techniques are beneficial. In addition, research could be performed to identify and create new statistics-based control techniques useful for accounting activities. We also believe that these techniques could be useful for other non-manufacturing short-run processes found in organizations.

\section{AUTHOR INFORMATION}

Timothy C. Krehbiel is Professor and Senior Associate Dean of the Farmer School of Business at Miami University. He has won numerous teaching awards including MBA Professor of the Year on three different occasions and the prestigious Instructional Innovation Award from the Decision Sciences Institute. Dr. Krehbiel's research focuses on statistical process control, capability metrics, and quality management systems. His work appears in numerous journals and he is also the co-author of Basic Business Statistics, Statistics for Managers Using Microsoft Excel, and Business Statistics: A First Course. Dr. Krehbiel earned his Ph.D. in statistics from the University of Wyoming. Dr. Timothy C. Krehbiel, Office of the Dean, Farmer School of Business, MSC 1002, 800 E. High Street, Miami University, Oxford, Ohio 45056, USA. E-mail: krehbitc@miamioh.edu 
Jan E. Eighme is a Senior Lecturer in the Department of Accountancy of the Farmer School of Business at Miami University. She earned her Ph.D. in accounting from Florida State University. She is a Certified Public Accountant. Dr. Eighme teaches accounting information systems and financial accounting courses. Her research interests include improvement of accounting processes and information technology controls. Dr. Jan E. Eighme, Department of Accountancy, 3094 Farmer School of Business, MSC 1002, 800 E. High Street, Miami University, Oxford, Ohio 45056, USA. E-mail: eighmeje@miamioh.edu (Corresponding author)

Douglas Havelka is an Associate Professor in the Information Systems and Analytics department of the Farmer School of Business at Miami University. He received his Ph.D. in management information systems from Texas Tech University. Dr. Havelka is a Certified Public Accountant and has worked as a project manager for electronic communication industry standards at AT\&T. His research areas of interest include information systems assurance, project management, and systems development methods. Dr. Douglas Havelka, Department of Information Systems and Analytics, 3095 Farmer School of Business, MSC 1002, 800 E. High Street, Miami University, Oxford, Ohio, 45056 USA. E-mail: havelkdj@miamioh.edu

\section{REFERENCES}

1. Abbas, N., Riaz, M., \& Does, J. M. M. (2011). Enhancing the performance of EWMA charts. Quality and Reliability Engineering International 27:821-833.

2. $\quad$ Aghili, S. (2009). A Six Sigma approach to internal audit. Strategic Finance (February):38-43.

3. Albin, S. L., Kang, L., \& Shea, G. (1997). An X and EWMA Chart for individual observations. Journal of Quality Technology 29(1):41-48.

4. Amin, R. W., \& Ethridge, R. A. (1998). A note on individual and moving range control charts. Journal of Quality Technology 30(1):70-74.

5. Brewer, P. C., \& Bagranoff, N. A. (2004). Near zero-defect accounting with Six Sigma. Journal of Corporate Accounting and Finance (January/February):67-72.

6. Brewer, P. C., \& Eighme, J. E. (2005). Using Six Sigma to improve the finance function. Strategic Finance (May):27-33.

7. Bruch, N. M. (1994). Using control charts to help manage accounts receivable. Healthcare Financial Management 48(7):44-48.

8. Davies, M. C. (2004). Discussion of supporting continuous monitoring using control charts. International Journal of Accounting Information System 5(2):131-134.

9. Dull, R. B., \& Tegarden, D. P. (2004). Using control charts to monitor financial reporting of public companies. International Journal of Accounting Information Systems 5(2):109-127.

10. Farnum, N. R. (1992). Control charts for short runs: Nonconstant process and measurement error. Journal of Quality Technology 24(3):138-144.

11. Friedman, M., \& Gitlow, H. (2002). The CPA in industry: Six Sigma primer for CPAs. The CPA Journal (November):56-59.

12. Goh, T., \& Xie, M. (2003). Statistical control of a Six Sigma process. Quality Engineering 15(4):587-592.

13. Grabski, S. (2004). Discussion of supporting continuous monitoring using control charts. International Journal of Accounting Information Systems 5(2):129-130.

14. Hahn, G. J., Doganaksoy, N., \& Hoerl, R. (2000). The evolution of Six Sigma. Quality Engineering 12(3):317-326.

15. Hofmann, A. (2005). Two controls, one result. Quality Progress (July):68-71.

16. Ho, S. K., \& Oddo A. R. (2007). Lessons learned from section 404 of the Sarbanes-Oxley Act. The CPA Journal (June):28-33.

17. Hostetler, D. (2010). A Six Sigma approach to internal audits. Journal of Accountancy (January):38-42.

18. Hutchins, G. (2002). Add value to quality audits. Quality Progress (September):74-75.

19. Juras, P. E., Martin, D. R., \& Aldhizer III, G. R. (2007). Adapting Six Sigma to help tame the SOX 404 compliance beast. Strategic Finance (March):36-41.

20. Koons, G. F., \& Luner, J. J. (1991). SPC in Low-Volume Manufacturing: A Case Study. Journal of Quality Technology 23(4):287-295.

21. Krehbiel, T. C., Eighme, J. E., \& Cottell, P. G. (2009). Morgan Systems, Inc.: Application of Six Sigma to the finance function. Journal of Accounting Education 27:104-123. 
22. Krehbiel, T. C., Havelka, D., \& Scharfenort, M. (2007). Process monitoring in accounting: Implementing pre-control charts. Journal of Applied Business Research 23(4):93-103.

23. LaComb, C., \& Senturk, D. (2006). The house that fraud built. Quality Progress (January):52-60.

24. Liebesman, S. (2005). Mitigate SOX risk with ISO 9001 and 14001. Quality Progress (September):91-93.

25. Logothetis, N. (1990). The theory of pre-control: A serious method or a colourful naivity? International Journal of Total Quality Management 1:207-220.

26. Long, J. A., Castellano, J. F., \& Harper, A. (2002). A user friendly financial reporting system. Quality Progress (January):60-66.

27. Lucas, J. M. (1982). Combined Shewhart-CUSUM quality control schemes. Journal of Quality Technology 14(2):51-59.

28. Lucas, J. M., \& Crosier, R. B. (1982). Fast initial response for CUSUM quality-control schemes: Give your CUSUM a head start. Technometrics 24(3):199-205.

29. Lucas, J. M., \& Saccucci, M. S. (1990). Exponentially weighted moving average control schemes: Properties and enhancements. Technometrics 32(1):1-12.

30. Mackertich, N. A. (2001). Precontrol vs. control charting: a critical comparison. Quality Engineering 2(3):253-260.

31. Marks, N. B., \& Krehbiel, T. C. (2009). Design and application of individuals and moving range control charts. Journal of Applied Business Research 25(5):31-40.

32. Montgomery, D. C. (2009). Introduction to Statistical Quality Control. $6^{\text {th }}$ edition. New Jersey: John Wiley and Sons, Inc.

33. Nanda, V. (2008). Two are better than one. Quality Progress (June):42-47.

34. Nelson, L. S. (1982). Control charts for individual measurements. Journal of Quality Technology 14(2):172-173.

35. Nelson, L. S. (1990). Monitoring reduction in variation with a range chart. Journal of Quality Technology 22(2):163-165.

36. Neuschler-Fritsch, D., \& Norris, R. (2001). Capturing financial benefits from Six Sigma. Quality Progress (May):39-44.

37. Reeve, J. M., \& Philpot, J. W. (1988). Applications of statistical process control for financial management. Journal of Cost Management (Fall):33-40.

38. Rhoads, T. R., Montgomery, D. C., \& Mastrangelo, C. M. (1996). Fast initial response scheme for the EWMA control chart. Quality Engineering 9(2):69-72.

39. Riaz, M., Abbas, N., \& Does, J. M. M. (2011). Improving the performance of CUSUM charts. Quality and Reliability Engineering International 27:415- 424.

40. Rigdon, S. E., Cruthis, E. N., \& Champ, C. W. (1994). Design strategies for individuals and moving range control charts. Journal of Quality Technology 26(4):274-287.

41. Roes, K. C. B., Does, R. J. M. M., \& Schurink, Y. (1993). Shewhart-type control charts for individual observations. Journal of Quality Technology 25:188-198.

42. Roth, H. P. (1990). Applications of control charts. The CPA Journal (April):90-95.

43. Rudisill, F., \& Clary, D. (2004). The management accountant's role in Six Sigma. Strategic Finance (November):35-39.

44. Rudisill, F., \& Clary, D. (2005). Six Sigma: Saving and making money. Chartered Accountant's Journal (April):21-25.

45. Senturk, D., LaComb, C., Neagu, R., \& Doganaksoy, M. (2006). Detect financial problems with Six Sigma. Quality Progress (April):41-47.

46. Shainin, D., \& Shainin, P. (1989). Pre-control versus $\bar{X}$ and R charting: Continuous or immediate quality improvement? Quality Engineering 1:419-429.

47. Snee, R. D., (2004). Weave Six Sigma into the fabric of an organization. Quality Progress (September):6972.

48. Stamitis, D. H. (2003). Six Sigma for financial professionals. New York: John Wiley \& Sons.

49. Steiner, S. H. (1999). EWMA control charts with time-varying control limits and fast initial response. Journal of Quality Technology 31(1):75-86.

50. Stimson, W. (2004). Sarbanes-Oxley and ISO 9000. Quality Progress (March):24-29.

51. Trip, A., Wieringa, J. E. (2006). Individuals charts and additional tests for changes in spread. Quality and Reliability Engineering International 22:239-249. 
52. Vardeman, S. B., \& Jobe, J. M. (1999). Statistical quality assurance methods for engineers. New Jersey: John Wiley and Sons, Inc.

53. Woodall, W. H. \& Adams, B. M. (1993). The statistical design of CUSUM Charts. Quality Engineering 5(4):559-570. 


\section{APPENDIX: IMPORTANT CONTROL CHART METHODOLOGY DEFINITIONS}

\section{Average Run Length (ARL)}

The average number of time periods a control chart goes without signaling an unstable condition is called the ARL. In an ideal state, the ARL for stable processes would be infinity, i.e., there would never be a false alarm. The ARL for stable processes is often referred to as the All-OK ARL. Likewise, in the ideal state, the ARL for unstable processes would be one, i.e., when a change in the process occurs, the control chart would always detect the change the very first time.

\section{False Alarm (Type I Error)}

If a control chart indicates that a stable process is unstable, a Type I error occurs. The error is a false alarm. In reality, the process is still maintaining the gains from the Six Sigma project, but the control chart is indicating that the process has changed. When a false alarm occurs, process owners search to identify a non-existing problem. In some instances the process owners may correctly identify that a false alarm occurred, but by this point a lot of effort was spent on the fruitless goose chase. In other cases, process owners invoke a change when one is not needed, and that typically leads to less desirable results.

\section{Lack of Sensitivity (Type II Error)}

If a control chart indicates that an unstable process is stable, a Type II error occurs. The control chart is suffering from a lack of sensitivity. In reality, the process is no longer maintaining the gains from the Six Sigma project, but the chart is not sensitive enough to detect the change. Improvements from all the hard work of the project are no longer being realized, and no effort is being exerted to correct the unknown change.

\section{Shewhart Control Chart}

This control chart was developed for monitoring an assembly-line manufacturing process. The center line represents the mean of a stable process. Upper and lower control limits are set at approximately three standard deviations from the mean. Frequent samples are taken, and the mean of each sample is plotted on the control chart. Plotted observations outside the limits or a pattern in the plotted observations (e.g., an increasing trend), indicate that the process may be unstable.

\section{Stable Process}

The output from a stable process exhibits a constant mean and a constant amount of variation. At the conclusion of the Improve Stage, the process should be in a stable state and, therefore, consistently experiencing the improvements. In the Control Stage, the process is monitored to make certain the process remains stable and, therefore, maintains the improved results. 
NOTES 